\section{NMP22 AS A URINE-BASED TUMOUR MARKER FOR BLADDER CANCER SCREENING IN A PROSPECTIVE COHORT OF CHEMICAL WORKERS FORMERLY EXPOSED TO AROMATIC AMINES: RESULTS OF THE UROSCREEN STUDY}

Dirk Taeger, ${ }^{1}$ Beate Pesch, ${ }^{1}$ Severine Huber, ${ }^{2}$ Michael Nasterlack, ${ }^{3}$ Gabriele Leng, ${ }^{4}$ Thomas Mayer, ${ }^{3}$ Katarzyna Gawrych, ${ }^{1}$ Nadine Bonberg, ${ }^{1}$ Harald Wellhäußer, ${ }^{5}$ Matthias Kluckert, ${ }^{5}$ Georg Johnen, ${ }^{1}$ Arnulf Stenzl, ${ }^{2}$ Thomas Brüning ${ }^{1}{ }^{1}$ Institute for Prevention and Occupational Medicine, Bochum, Germany; ${ }^{2}$ Eberhard-KarlsUniversity, Tübingen, Germany: ${ }^{3} B A S F$ SE, Ludwigshafen, Germany; ${ }^{4}$ Currenta GmbH \& Co. OHG (formerly BAYER AG), Leverkusen, Germany; ${ }^{5}$ Berufsgenossenschaft Rohstoffe und Chemische Industrie, Heidelberg, Germany

10.1136/oemed-2011-100382.12

Objectives Cancer of the urinary bladder ranks among the four leading cancers among men in Germany. Because bladder cancer can be successfully treated, patients will benefit from early detection. Due to a lack of clinical signs besides haematuria, urine-based tumour markers have been proposed for early detection. One aim of the prospective UroScreen cohort is to evaluate the cancer predictive values of nuclear matrix protein NMP22 in bladder cancer screening.

Methods Between 2003 and 2010 active or retired workers of two chemical plants took part in an annual voluntary bladder cancer screening program. All men were formerly exposed to aromatic amines. A total of 7092 urine samples from 1609 workers were collected for determination of urine status, cytology, and NMP22. Reference pathology was performed.

Results During the study 20 bladder tumours occurred in nineteen workers, including two papilloma, 12 incident, and five recurrent bladder tumours. We observed a total of 224 positive NMP22 tests (cut point: $10 \mathrm{U} / \mathrm{ml}$ ). NMP22 sensitivity was about $97 \%$ for all tumour types, NMP22 specificity ranged between $25 \%$ for high-grade and $40 \%$ for low-grade tumours. A similar pattern was observed for the predictive values (PVs). Negative PV was higher than 99\%, and the positive PV ranged between $4 \%$ and $12 \%$.

Conclusions NMP22 cannot be recommended for bladder cancer screening in a symptom-free population due to the low incidence of bladder cancer and the high false-positive rate. However, the high specificity for low-grade tumours renders this marker suitable for the follow-up of patients on recurrent bladder cancer. 